\title{
Micropolíticas mapuche contra el despojo en el Chile neoliberal. La disputa por el lafkenmapu (territorio costero) en Mehuín
}

\author{
Mapuche micropolitics against dispossession in neoliberal Chile. The \\ dispute for the lafkenmapu (coastal territory) in Mehuín
}

\author{
Héctor Nahuelpan Moreno*
}

\begin{abstract}
Resumen: Este artículo analiza la historia de organización y auto-defensa que desde 1996 se ha desarrollado en la comunidad costera de Mehuín (Región de los Ríos, Chile), frente a la construcción de un ducto para evacuar al mar los desechos de una industria de celulosa. Esta industria pertenece a uno de los principales productores mundiales en el rubro forestal y uno de los grupos económicos más importantes en Chile (ARAUCO-Angelini). Analizo las estrategias de resistencia desplegadas por mapuche-lafkenche frente a la agresión del capitalismo extractivo, que en la actual fase de globalización neoliberal actualiza patrones históricos de despojo racializado sobre pueblos indígenas. Argumento que uno de los principales efectos de este antagonismo, ha sido la irrupción de identidades políticas mapuche que desarrollan concepciones de autonomía como construcciones cotidianas, desafiando las nuevas formas regulatorias de poblaciones indígenas desplegadas por el estado y el capital.
\end{abstract}

Palabras clave: Mapuche, racismo, Chile, neoliberalismo, despojo, micropolíticas.

\footnotetext{
* Mapuche. Doctor en Antropología por el Centro de Investigaciones y Estudios Superiores en Antropología Social (CIESAS, México D.F.). Profesor del Departamento de Ciencias Sociales de la Universidad de Los Lagos e integrante de la Comunidad de Historia Mapuche. Artículo escrito en el marco del Proyecto FONDECYT-Postdoctorado N 3140625 “Otras historias, otros movimientos mapuche. Estudio sobre respuestas políticas cotidianas frente al colonialismo en Chile (siglo XX), del cual soy investigador responsable. Correo electrónico: hnahuelpan@gmail.com.
} 


\begin{abstract}
This article analyzes the history of a Chilean coastal community's organizing to prevent the construction of a sewage pipe to dump industrial cellulous waste into the sea. This sewage pipe would be constructed by one of the largest cellulose producers in the world, and one of the most powerful economic groups in Chile (ARAUCO-Angelini). I analyze the strategies of resistance developed by the Mapuche-Lafkenche in opposition to the aggression of extractive capitalism, which in the current process of neoliberal globalization, revives historic patterns of racial dispossession against indigenous peoples. I argue that one of the main effects of the dispute has been the resurgence of new Mapuche political identities, which develop concepts of autonomy as daily construction, confronting the new forms of regulation of indigenous populations deployed by the state and capital.
\end{abstract}

Keywords: Mapuche, Racism, Chile, Neoliberalism, Dispossesion, Micropolitics

Recibido: 22 marzo 2016

Aceptado: 7 junio 2016

\title{
Introducción
}

El capital nace goteando sangre y porquería de pies a cabeza, por todos los poros. ${ }^{1}$

Mehuín es un poblado costero del sur de Chile (Región de los Ríos), ubicado en la desembocadura del río Lingue en el Océano Pacífico. Allí convive población mapuche con familias de antiguos campesinos chilenos que llegaron a la zona durante la primera mitad del siglo XX y pescadores artesanales que arriban después del maremoto de 1960 atraídos por la abundancia de recursos marinos. Actualmente la vida económica de la gente de Mehuín y sus alrededores depende del ecosistema marino, que proporciona las condiciones para practicar la pesca y el

${ }^{1}$ Karl Marx, El Capital, Libro I, Barcelona, Ediciones Grijalbo, 1976, 407. 
buceo artesanal, la recolección de algas, el desarrollo de pequeños emprendimientos turísticos, el comercio minorista e informal de diversas especies de mariscos, algas y peces.

Mehuín es el poblado al que también se vinculan otras comunidades rurales aledañas como Cheuque, Piutril, Yeco, Misisipi, Mehuín Bajo y Mehuín Alto, Maiquillahue, Chan Chan, Quillalhue y Alepúe, cuya población se reconoce como mapuche-lafkenche (gente del mar) y vive en pequeñas hijuelas de tierra. Estas últimas que se originan en la división de los Títulos de Merced otorgados por el Estado en la zona entre los años 1914 y 1919, como en los títulos de propiedad entregados mediante la ley de propiedad austral desde la década de $1930 .^{2}$

Hasta el año 1995 Mehuín era un lugar prácticamente desconocido en Chile, una localidad que "ni siquiera aparecía en el mapa", como precisa uno de sus habitantes. ${ }^{3}$ Sin embargo desde ese año Mehuín comenzó a adquirir un insólito protagonismo, al emerger como una zona de resistencia contra la desenfrenada arremetida del capitalismo extractivo sobre territorio mapuche en el contexto democrático postdictatorial chileno. ¿Qué produjo esta emergencia?

A fines del año 1995 un grupo de profesionales llegó a Mehuín presentándose ante los pescadores como funcionarios del gobierno de Eduardo Frei Ruiz-Tagle y declarando que efectuarían estudios de batimetría (profundidad marina) para el desarrollo de futuros trabajos de mejoramiento de la desembocadura del río Lingue. El proyecto interesó a los pescadores y colaboraron con los profesionales, por las dificultades que esta desembocadura (conocida como "La Barra") tiene en el ingreso mar adentro de las embarcaciones artesanales y los riesgos a los que se exponen diariamente por la acumulación de bancos de arena que genera el oleaje y las corrientes. Uno de los pescadores recuerda que los estudios de batimetría se extendieron aproximadamente quince días y que al concluir celebraron el proyecto que, según ellos, mejoraría sus condiciones de vida y la seguridad de sus labores cotidianas de pesca artesanal. Sin embargo fue durante la celebración que los anfitriones se percataron del trasfondo que explicaba la presencia de los afuerinos:

\footnotetext{
2 Información obtenida de la revisión del Fondo Comisión Radicadora de Indígenas, Archivo General de Asuntos Indígenas. También del archivo de la SEREMI Bienes Nacionales de la Región de Los Ríos.

${ }^{3}$ Eliab Viguera, entrevista con el autor, 27 de Junio, 2012.
} 
Héctor Nahuelpan, Micropolíticas mapuche contra el despojo en el Chile neoliberal. La disputa por el lafkenmapu (territorio costero) en Mehuín, Izquierdas, 30, Octubre 2016: 89-123

Estábamos compartiendo cuando uno de los que estaba borracho nos dijo: "nosotros no somos del gobierno, no vamos a mentir. Nos contrató una empresa de celulosa que se va a instalar en San José y quiere hacer estudios para botar sus desechos en el mar". Así nos dijo, y todos nos quedamos escuchando, ¡hasta se nos llegó a pasar la borrachera!

Desde ese día los rumores sobre la construcción de una industria de celulosa en la Comuna de Mariquina y la evacuación de sus desechos en la bahía, comenzaron a circular entre la población local y generando preocupación por los impactos que iba a tener en el medioambiente. Estos rumores se corroboraron el año 1996 cuando el gobierno de Frei Ruiz-Tagle hizo pública la construcción de la industria, que se emplazaría a unos cuarenta kilómetros al sureste de Mehuín. El proyecto había ingresado al Sistema de Evaluación de Impacto Ambiental (SEIA) a inicios de octubre de 1995, fue aprobado a fines de mayo del año siguiente por la Comisión Regional del Medioambiente (COREMA) y consistía en la producción de celulosa blanqueada de pinus radiata y eucalyptus del orden de quinientos cincuenta mil toneladas anuales. La materia prima de la industria de celulosa provenía del enclave de monocultivo forestal emplazado en el centro-sur de Chile, cuyos nocivos impactos sobre las aguas superficiales y napas subterráneas, suelos y biodiversidad, habían contribuido a activar diversas movilizaciones mapuche en las regiones del Bío Bío y la Araucanía. ${ }^{5}$ No obstante lo anterior, la industria de celulosa era, para las autoridades políticas chilenas de entonces, una de las "más grandes y modernas de Sudamérica... un proyecto de suma importancia no solamente para la provincia de Valdivia, no solamente para la región sino para el país". 6

Desde que se inicia el conflicto en Mehuín generó el interés de investigadores del campo de la antropología, geografía y el derecho principalmente. En sus trabajos éstos han analizado cómo el paisaje condicionó las

\footnotetext{
${ }^{4}$ M.N. Entrevista con el autor, 24 de enero, 2014. Las iniciales de nombres y apellidos corresponden a personas que optaron por mantener su anonimato.

5 Tito Tricot, "Lumako: punto de inflexión en el desarrollo del nuevo movimiento mapuche", Revista de Historia Actual 19, 2009, 77-96; Fernando Pairican y Rolando Alvarez, "La Nueva Guerra de Arauco: la Coordinadora Arauco Malleco y los nuevos movimientos de resistencia mapuche en el Chile de la Concertación (1997-2009)", Revista Izquierdas 10, 2011, 66-84; Fernando Pairican, Malón. La rebelión del movimiento mapuche, 1990-2013. Santiago de Chile, Pehuen Editores, 2014, 93-113.

${ }^{6}$ Diario Austral de Valdivia, "Es muy delicado oponerse por oponerse", 23 de noviembre de 1996.
} 
Héctor Nahuelpan, Micropolíticas mapuche contra el despojo en el Chile neoliberal. La disputa por el lafkenmapu (territorio costero) en Mehuín, Izquierdas, 30, Octubre 2016: 89-123

respuestas de la población frente a la presión del capital extractivo; los modos en que fue construyéndose un sentido de comunidad durante la acción colectiva; el actuar pro-empresarial de los representantes de distintos gobiernos democráticos postdictatoriales; las violaciones a los derechos humanos de la población mapuchelafkenche, entre otros temas. ${ }^{7}$ Los aportes de estas investigaciones han sido relevantes, contribuyendo a visibilizar en el campo académico el antagonismo en la bahía de Mehuín y a comprender la conflictividad entre el estado, las empresas y el pueblo mapuche más allá de la región de la Araucanía. No obstante lo anterior, este artículo busca ampliar y profundizar en el conocimiento de esta experiencia territorializada de organización y defensa, desde la perspectiva de un investigador mapuche que proviene de la localidad de Mehuín y que mediante el trabajo de reconstrucción histórica ha buscado fortalecer la cohesión social y territorial mapuche-lafkenche. Este artículo es, por tanto, el resultado de un ejercicio escritural política e intelectualmente situado $^{8}$ que se basa en la comprehensión

\footnotetext{
7 Juan Skewes, "Conocimiento científico y conocimiento local. Lo que las universidades no saben acerca de lo que actores locales saben", Cinta de Moebio 19, 2004, 22-37; Julio García, Ingrid Henríquez y Daniella Ramírez, "Caso CELCO: una falla multisistémica", Revista de Derecho Ambiental, 2, 2005, 141-166; Daniela Pino, Aprendizajes y olvidos de una construcción política y patrimonial de la naturaleza: memoria colectiva del conflicto por la bahía de Maiquillahue en las nuevas generaciones de la comunidad de Mehuín, Tesis para optar al Título de Antropóloga, Universidad Austral de Chile, 2005; Claudia Sepúlveda y Pablo Villarroel, "Desastre ecológico de CELCO en el Santuario Río Cruces: trizadura institucional y retroceso democrático", Sara Larraín y Pamela Poo (eds.), Conflictos por el agua en Chile: entre los derechos humanos y las reglas del mercado, Santiago de Chile, Programa Chile Sustentable, 2010, 318-338; Debbie Guerra y Juan Skewes, "Acumulación por desposesión y respuestas locales en el remodelaje de los paisajes estuariales del sur de Chile", Chungará. Revista de Antropología Chilena 42: 2, 2010, 451-463; Bárbara Morales, "Defensa del medioambiente y ciudadanía: etnografía de los procesos de construcción de comunidad en el curso de la acción colectiva. El caso del Comité de Defensa del Mar en la zona costera de Mehuín, Chile", Persona y Sociedad 27:2, 2013, 145-167; Palma, Karen, Desarrollo forestal en la Región de los Ríos. Análisis de la resistencia y el impacto en la comunidad Mapuche Lafkenche en la Bahía de Maiquillahue 1997-2007, Tesis para optar al título de Profesora de Historia y Ciencias Sociales, Universidad Austral de Chile, 2013.

8 Sobre la teoría del punto de vista (Stand Point Theory) y la noción de conocimientos situados, véase: Nancy Hartsock, "The feminist standpoint", Sandra Harding y Merrill Hintikka (eds.), Discovering reality. Feminist perspectives on epistemology. Metaphysics, methodology and philosophy of science, Boston y Londres, D. Riedel Publishing Company, 1983, 283-310; Donna Haraway, Ciencia, cyborgs y mujeres. La reinvención de la naturaleza. Madrid, Catedra, 1995; Jérome Baschet, "Punto de vista e investigación: el caso del zapatismo", Desacatos, 33, 2010, 189201.
} 
"desde adentro" que proporciona el trabajo de campo (auto) etnográfico, el que a su vez se complementa con teorizaciones utilizadas como "caja de herramientas" para ampliar la capacidad analítica de las problemáticas abordadas.

De este modo intento responder: ¿cómo se fue configurando cotidianamente el conflicto y cuáles han sido las principales estrategias de resistencia de las y los defensores del mar para contener la contaminación del lafkenmapu (territorio costero)?, y seguidamente ¿cuáles son las razones que explican la efectividad de estas estrategias? Estas preguntas y sus respuestas adquieren relevancia si se considera que el proceso de defensa y resistencia en Mehuín junto con desafiar la alianza estado-empresarial, ha confrontado a un adversario poderoso (Grupo Arauco-Angelini) que constituye uno los principales grupos económicos en Chile y uno de los principales exportadores de celulosa a nivel mundial.

En términos de debates teórico-políticos, sostengo que aún cuando el conflicto de Mehuín se inscribe en un escenario nacional y global más amplio de antagonismos con el capitalismo extractivo, asociado a un patrón global de acumulación basado en la desposesión. ${ }^{9}$ Para el caso mapuche, como en el de otros pueblos indígenas y afrodescendientes en América, este patrón de acumulación adopta rasgos particulares al actualizar procesos históricos que profundizan la violencia sobre vidas y espacios geográficos racializados que al ser valorados desigualmente por la presencia de población indígena, se encuentran expuestos a la violencia, a la muerte y se transforman en blancos de políticas neocoloniales basadas en la eliminación de vidas humanas y no-humanas para vaciar territorios y reconectarlos a los mercados nacionales y/o globales. Considero que una aproximación analítica a estos procesos puede realizarse a distintas escalas (desde lo local, lo nacional o global), sin embargo en este artículo priorizo las acciones, voces y análisis de los propios actores que han sido protagonistas de la defensa del mar. Voces y análisis que nos proporcionan una ventana etnográfica que no sólo permite dar cuenta de la importancia de la cotidianeidad como espacio de organización, defensa y resistencia frente al capitalismo extractivo en el Chile neoliberal. Sino también la forma en que desde estas experiencias territorializadas

\footnotetext{
${ }^{9}$ La noción de "acumulación por desposesión" ha sido desarrollada por el geógrafo marxista David Harvey a partir de los análisis de Marx sobre la "acumulación originaria" y de Luxemburgo sobre el imperialismo y la política colonial. Al respecto véase: David Harvey, El nuevo imperialismo, Madrid, Ediciones AKAL, 2004; Marx, op.cit., 359-410; Rosa Luxemburgo, La acumulación del capital, Barcelona, Ediciones Grijalbo, 1972.
} 
Héctor Nahuelpan, Micropolíticas mapuche contra el despojo en el Chile neoliberal. La disputa por el lafkenmapu (territorio costero) en Mehuín, Izquierdas, 30, Octubre 2016: 89-123

de antagonismo, surgen micropolíticas de resistencia que en su despliegue cotidiano prefiguran horizontes de vida alternativos que son los que precisamente violenta y busca exterminar el capital -y estado como su garante- al transformarse en sus principales obstáculos. ${ }^{10}$

Para responder las interrogantes de este artículo, comenzamos reconstruyendo la forma en que fue gestándose el proceso organizativo de la población local y explicando cómo el control territorial se constituyó en la principal plataforma de auto-defensa. Seguidamente se analizan las estrategias del grupo ARAUCO para desarticular el entramado social-comunitario conformado por pescadores artesanales y comunidades mapuche-lafkenche. Luego enfocamos en las estrategias de defensa de las comunidades, para finalmente concluir abordando algunas de las dimensiones menos exploradas en los estudios sobre la conflictividad territorial que protagonizan pueblos indígenas: la emergencia o irrupción de nuevas subjetividades e identidades políticas mapuche que desafían las formas regulatorias de poblaciones indígenas que son desplegadas en el contexto del proyecto cultural neoliberal. ${ }^{11}$

\footnotetext{
${ }^{10}$ Por "micropolíticas de resistencia mapuche", me refiero a las acciones diversas y múltiples que sitúan la cotidianeidad como espacio estratégico de impugnación, corrosión, transformación de relaciones de poder y condiciones de opresión racial e histórica. Al respecto véase Héctor Nahuelpan, " 'Nos explotaron como animales y ahora quieren que no nos levantemos'. Vidas despojables y micropolíticas de resistencia mapuche", Enrique Antileo, Herson Huinca y Luis Cárcamo-Huechante (Eds.), Awükan ka kuxankan zugu Wajmapu mew. Violencias coloniales en Wajmapu, Temuco, Ediciones Comunidad de Historia Mapuche, 2015, 271-300. Uso la noción de micropolítica, basándome en los estudios sobre resistencia cotidiana de James Scott, Los dominados y el arte de la resistencia, México, Ediciones Era, 2000; Romana Falcon, México descalzo, México, Plaza y Janés, 2002. También a partir de la los trabajos de Felix Guattari y Suely Rolnik, Micropolítica. Cartografías del deseo, Madrid, Traficantes de Sueños, 2006; Michel Foucault, Microfísica del poder, Madrid, La Piqueta, 1991.

${ }^{11}$ El neoliberalismo no tiene que ver solamente con políticas económicas o reformas al Estado, sino también con un proyecto cultural que promueve la formación de nuevas subjetividades y relaciones entre la ciudadanía, el Estado y el capital. Para el caso de los pueblos indígenas este proyecto cultural se expresa en la emergencia de un nuevo régimen de gobernanza denominado "multiculturalismo neoliberal" que opera mediante la promoción y el reconocimiento de derechos e identidades culturales indígenas, mientras paralelamente excluye o violenta identidades políticas y movilizaciones que desafían el racismo estructural, el colonialismo histórico y la libre circulación del capital. Uno de los análisis más relevantes sobre el multiculturalismo neoliberal como proyecto cultural es el de Charles R. Hale, Does multiculturalism menace? Governance, cultural rights and the politics of identity in Guatemala, Journal of Latin American Studies 34: 3, 2002, 485-524.
} 


\section{El Comité de Defensa del Mar y el control territorial}

Cuando a mediados de los años noventa la población de Mehuín y sus alrededores supo de la amenaza que representaba la eventual descarga de desechos industriales en la bahía, una de sus primeras reacciones fue desarrollar un mayor grado de información sobre el proyecto, sus eventuales impactos, así como los adversarios que enfrentarían. En ello el conocimiento científico jugó un rol importante, no obstante el conocimiento que tenían habitantes de la bahía sobre las consecuencias ambientales generadas en Chile por otras industrias de celulosa también propiedad de ARAUCO-, fue crucial en la formación de las primeras percepciones. Como sostiene Eliab Viguera, uno de los dirigentes locales: "vecinos de Mehuín que habían estado en la zona de Arauco, en la zona de Laraquete, vivieron lo que es estar cerca de una planta de celulosa y los desastres que provoca". ${ }^{12}$

Para construir el ducto de evacuación de residuos industriales en el mar, en ese entonces la empresa debía efectuar mediciones y trabajos en terreno para presentar un Estudio de Impacto Ambiental (EIA) que, de acuerdo a la normativa ambiental, 13 demostrara la factibilidad del proyecto. Por la permisividad de la normativa y la subordinación a los intereses del capital, además de la colusión de las burocracias y políticos de gobierno con grupos económicos, una de las principales respuestas de la población local fue tomar el control del territorio amenazado, bloqueando el ingreso de personas relacionadas con la empresa. Acción que se transformó en estrategia clave de auto-defensa y que paralelamente estaba ensayándose por otras comunidades mapuche de las regiones del Bio Bio y Araucanía en las recuperaciones de tierras en poder de empresas forestales, entre ellas ARAUCO. ${ }^{14}$

La primera expulsión de profesionales contratados por la empresa fue el diecisiete de junio de 1996, día en que se realizó la primera asamblea que originó el Comité de Defensa de Mehuín. Dos días después, se efectuó una reunión donde participaron representantes del comité, del gobierno regional, de la Universidad

\footnotetext{
12 Viguera, op. cit.

${ }^{13}$ Me refiero a la Ley sobre Bases Generales del Medioambiente ( $\left.\mathrm{N}^{\circ} 19.300\right)$ promulgada el año 1994.

14 Sobre el "control territorial" como estrategia de autonomía, véase: Hector Llaitul y Jorge Arrate, Weychan. Conversaciones con un weychafe en la prisión política, CEIBO, Santiago de Chile, 2012.
} 
Austral de Chile, así como representantes de ARAUCO. La reunión se extendió aproximadamente tres horas, pero fue reveladora de los actores involucrados en el conflicto y el rumbo que tomaría éste. Viguera recuerda que:

Los representantes de la empresa conversaron del proyecto, de la danza de millones de dólares. Al final uno de los gerentes nos dijo prepotente "vamos a construir un ducto". Eso nos enfureció porque vimos el perfil de la empresa, prepotente y acostumbrada a poner el pie encima a la gente. También ese gerente les dijo a los políticos "si ustedes se oponen, nos llevamos el proyecto a otro lado" y los políticos quedaron asustados, como diciendo: ipor favor, no se lleven el proyecto!

De esta forma y como conclusión de esa reunión, Viguera sostiene que:

El panorama quedó claro para nosotros, una empresa prepotente, políticos subordinados a los intereses del poder económico, y nosotros, una comunidad que ni siquiera aparece en el mapa que iba a hacer la vida imposible a la empresa, no iba a permitir la contaminación de nuestro territorio y que estaba dispuesta a llegar hasta las últimas consecuencias. ${ }^{15}$

En este escenario donde las autoridades de gobierno de alinearon con los intereses de ARAUCO, el comité se conformó desde un espectro diverso de personas, organizaciones del poblado y sus territorios aledaños: pescadores artesanales, juntas de vecinos, pequeños comerciantes y comunidades mapuchelafkenche. El territorio costero devino en núcleo articulador de los diversos sentidos de pertenencia, que se nutrían de experiencias de vida y memorias, las que convergían en una identidad colectiva que sustentaba la defensa del territorio y que se modelaba desde procesos cotidianos de auto-organización como asambleas, acciones de vigilancia, "ollas comunes", etc. En el caso mapuche, paralelamente se conformó la Coordinadora de Comunidades MapucheLafkenche, que designó a cuatro dirigentes para su representación en el comité. En una de sus primeras declaraciones la coordinadora trazó su posición en el conflicto argumentando que la resistencia a ARAUCO no sólo obedecía a los impactos ambientales que tendría la evacuación de desechos en el mar, sino ante todo a las

\footnotetext{
15 Viguera, op. cit.
} 
implicancias culturales, políticas e históricas del proyecto teniendo en cuenta la ocupación ancestral mapuche del lafkenmapu. ${ }^{16}$

De esta forma el comité se organizó mediante la designación de representantes de organizaciones y comunidades locales, gestando alianzas con pescadores artesanales de otras zonas del sur de Chile; organizaciones mapuche de las regiones del Bio Bio, Araucanía y Los Lagos; como también con agrupaciones ambientalistas, investigadores universitarios y profesionales simpatizantes que respaldaban la oposición al ducto y colaboraban con la defensa del mar.

Desde el inicio del conflicto los integrantes del comité visualizaron que confrontaban un adversario importante y que la materialización del proyecto les despojaría de su fuente de vida: el mar. La industria de celulosa que proyectaba evacuar sus desechos en Mehuín era y es propiedad de ARAUCO, grupo controlado por la familia Angelini que arriba a Chile desde Italia después de la segunda guerra mundial. La fortuna económica de Angelini se acumuló en la dictadura militar, principalmente con la adquisición a bajo costo de antiguas empresas públicas que fueron privatizadas, la apropiación vía remates y compras de tierras a precios irrisorios que habían sido expropiadas a campesinos y mapuche durante la reforma agraria, así como mediante el subsidio estatal a la actividad forestal recibido con el Decreto Ley N ${ }^{\circ} 701$ del año $1974 .{ }^{17}$ Sus acciones se diversificaban en el sector financiero, naviero, de los combustibles, la minería, la actividad pesquera y forestal. En este último rubro ARAUCO actualmente posee más de un millón de hectáreas de plantaciones forestales, ${ }^{18}$ emplazadas en el histórico territorio mapuche de Ngulumapu -regiones de Bío Bío, Araucanía, Los Ríos y los Lagos. Superficie que duplica la cantidad de tierras actualmente en posesión mapuche. ${ }^{19}$

\footnotetext{
${ }^{16}$ Coordinadora de Comunidades Mapuche Lafkenche, Declaración pública, 20 de junio de 1996.

17 Fernando, Dhase, Mapa de la extrema riqueza, Santiago de Chile, Aconcagua, 1979. Para mayor información sobre la formación, expansión y consolidación de la industria forestal en la zona centro-sur de Chile, véase: Klubock, Thomas, La Frontera, Forest and ecological conflict in Chile's frontier territory, Durham, Duke University Press.

18 Arauco, Memoria Anual 2011, Santiago de Chile, 2011, 30.

${ }^{19}$ José Aylwin, Nancy Yáñez y Rubén Sánchez, Pueblo mapuche y recursos forestales en Chile: devastación y conservación en un contexto de globalización económica, Santiago de Chile, IWGIA / Observatorio Ciudadano, 2013.
} 
En este escenario confrontar a ARAUCO no era un trabajo sencillo, pues tenía el respaldo de autoridades políticas centrales, regionales y municipales. Además para entonces los gobiernos democráticos habían demostrado que no desmantelarían la principal herencia de la dictadura militar, el modelo neoliberal, sino que sobre la marcha lo hicieron cada vez más suyo incorporando ajustes en materia de equidad mediante programas sociales. ${ }^{20}$ En este sentido, la oposición a ARAUCO no sólo representaba una confrontación con el capitalismo extractivo, también develaba desde esta experiencia local de resistencia los límites de la "transición democrática" chilena.

Es por ello que en este escenario adverso desde el comité se conformaron comisiones distribuyéndose funciones para controlar el territorio: vigilancia en las dos entradas por tierra a Mehuín; participación de familias ante eventuales ingresos de personas relacionadas con la empresa; disposición de embarcaciones de pescadores artesanales para vigilar en el mar; comunicación con pescadores artesanales de zonas aledañas; vigilancia desde los cerros de la cordillera de la costa por familias mapuche. El "discurso público" 21 del comité durante esta primera etapa del conflicto (1996 - 1998), recurría estratégicamente al "derecho a vivir en un medioambiente libre de contaminación" estipulado en la constitución chilena. ${ }^{22}$ Sin embargo bajo este discurso público, las razones que movilizaban la defensa y el control territorial eran diversas e iban desde la voluntad de resguardar el ecosistema que proporcionaba la supervivencia económica de las familias, la protección por su potencial turístico, hasta el significado que tenía para los mapuche la contaminación del territorio costero habitado históricamente. Como sostiene Boris Hualme, werken (vocero) de las comunidades:

El tema de fondo era la defensa del mar. Pero nosotros también sabíamos que para todos los que estábamos en la defensa no tenía el mismo sentido. Pero era necesario hacer alianzas. Para los pescadores de Mehuín era un asunto de vivir del mar, casi netamente económico. Pero para nosotros, como

\footnotetext{
${ }^{20}$ Corvalán, Luis, Del anticapitalismo al neoliberalismo en Chile, Santiago de Chile, Editorial Sudamericana, 2001, 446; Garreton, Manuel, Neoliberalismo corregido y progresismo limitado. Los gobiernos de la Concertación en Chile, 1990-2010, Santiago de Chile, Editorial ARCIS / CLACSO, $2012,171$.

${ }^{21}$ Sobre el uso del "discurso público" y el "discurso oculto" en las dinámicas de resistencia, véase: James Scott, Los dominados y el arte de la resistencia, México, Ediciones Era, 2000, 71-96.

${ }_{22}$ Constitución Política de la República de Chile, Editorial Jurídica de Chile, Santiago, 1993, Artículo $18, \mathrm{~N}^{\circ} 8$, inciso primero.
} 
mapuche era y sigue siendo un asunto de vivir en el mar. Somos parte del lafkenmapu, con todo lo que eso significa en cuanto a cultura, filosofía, idioma, autonomía, identidad y dentro de eso lo productivo. Entonces en el mismo conflicto también nos jugábamos la lucha por la autonomía mapuche. ${ }^{23}$

En contraste con la oposición local, representantes de ARAUCO y del gobierno chileno argumentaron que la defensa del mar amenazaba los espacios laborales que abrirían la industria y la construcción del ducto. El discurso centrado en el trabajo y desarrollo como justificación del extractivismo, circulaba en una coyuntura donde el aumento de la cesantía y la disminución del crecimiento económico preocupaba al gobierno de entonces, por los efectos que estaba teniendo la "crisis asiática" en la economía chilena. De allí que desde este discurso oficial, la defensa del mar era calificada como una "oposición sinsentido" ante la "verdadera explosión de desarrollo" que acrecentaría los indicadores de crecimiento económico, como argumentó un senador oficialista de la Concertación de Partidos por la Democracia. ${ }^{24}$ En sintonía con esta declaración, Victor Renner, gerente del "Proyecto Valdivia" de ARAUCO argumentaba en la sucursal regional del principal medio de prensa escrita en Chile, que "lo que nos mueve no es otra cosa que colaborar con el desarrollo del país, de la región, a través de empleo y estamos convencidos de que lo que estamos haciendo es algo que está técnicamente bien". ${ }^{25}$

Las declaraciones de los políticos oficialistas y los representantes de la empresa, se hallaban lejos de convencer a la población local. De modo que la defensa del territorio durante la primera etapa de conflicto produjo enfrentamientos mar adentro con personal de la empresa y de la Armada de Chile; así como la confrontación con carabineros (policía) cuando en varias ocasiones se instalaron barricadas para bloquear los accesos al poblado y controlar el territorio amenazado. Así las estrategias de acción directa desplegadas por el comité rindieron sus frutos, pues frente a la oposición de la población local el año 1998

\footnotetext{
${ }^{23}$ Boris Hualme, entrevista con el autor, 14 de enero, 2011.

${ }^{24}$ La Segunda, "Planta de celulosa Valdivia significa una verdadera explosión de desarrollo", 19 de marzo de 1997.

${ }^{25}$ Diario Austral de Valdivia, "No hay ningún conflicto que mediar", 21 de octubre de 2007.
} 
ARAUCO desistió de evacuar los residuos en el mar y optó por el río Cruces como zona de descarga.

La industria inició sus operaciones el año 2004, evacuando sus desechos en el río Cruces. Sin embargo al año siguiente se hizo público el desastre ambiental provocado por ésta, específicamente con la muerte masiva de diversas especies de aves acuáticas como los cisnes de cuello negro (cignus melancoryphus). Frente al desastre, COREMA resolvió que la empresa debía buscar una nueva alternativa de descarga, re-emergiendo la zona de Mehuín como basurero para la industria de celulosa, con un claro intervencionismo del gobierno de Ricardo Lagos. Este último que el año 2005 sin que se efectuasen estudios ambientales como lo exigía el "estado de derecho", manifestó su compromiso con ARAUCO afirmando que "tiene que haber una forma definitiva de resolver el problema de los residuos, particularmente de los residuos sólidos y líquidos a través de un ducto que llegue al mar". ${ }^{26}$

De este modo, en septiembre del año 2005 se reinicia el conflicto retomándose las estrategias de control territorial por la población local, esta vez rearticulada bajo el nombre de Comité de Defensa del Mar. Las movilizaciones se radicalizaron el quince de agosto de 2006 cuando embarcaciones contratadas por ARAUCO ingresaron a la bahía resguardadas por la Armada de Chile. En este episodio, frente a la oposición de los pescadores y comunidades mapuche, efectivos de la Armada abrieron fuego contra los defensores del mar, quienes finalmente lograron expulsar tanto a las embarcaciones de la Armada como a las de la empresa que pretendían realizar los estudios de batimetría. Para los defensores y defensoras del mar impedir el desarrollo de estudios y mediciones era estratégico, pues "si no tomaban las muestras, no era posible que hagan el estudio. Si no hacían el estudio, era imposible presentar a evaluación el proyecto. Si no se evaluaba el proyecto, no se autorizaría su construcción. Como las autoridades del gobierno estaban con la empresa y contra nosotros, había que impedir que el estudio se concretara". 27

\footnotetext{
${ }^{26}$ Citado por Alfredo Seguel, "Crónicas de desencuentros: el gobierno de Ricardo Lagos versus el movimiento social mapuche”, Nancy Yañez y José Aylwin (eds.), El gobierno de Lagos, los pueblos indígenas y el "nuevo trato", Santiago de Chile, LOM Ediciones, 2007, 130.

27 Viguera, op. cit.
} 
El episodio de agosto del 2006 significó una victoria temporal para defensores y defensoras del mar. Fue un evento inédito de resistencia que confrontaba el poder económico que representaba el grupo ARAUCO y el monopolio de la violencia estatal que resguardaba los intereses de la empresa. Mehuín se constituía en un referente de organización y movilización que, desde abajo y articulando una diversidad de actores, buscaba contener las transformaciones que proyectos de inversión pública y privada producían en territorios locales durante el contexto democrático postdictatorial. Cabe recordar que para entonces comunidades mapuche en las regiones del Bío Bio y Araucanía principalmente, habían iniciado un ciclo de recuperación de tierras que se encontraban en posesión de particulares y empresas forestales; el gobierno de Lagos había puesto en marcha la estrategia de contrainsurgencia denominada "operación paciencia", para contener las movilizaciones mapuche y encarcelar a sus principales liderazgos; ${ }^{28}$ a la vez que habían estallado diversos conflictos territoriales en el sur de Chile con otros proyectos extractivos y energéticos, cuyos desenlaces eran favorables a los grupos económicos nacionales y transnacionales. Un caso dramático eran las centrales hidroeléctricas de Ralco en la pre-cordillera de los Andes, que luego del quiebre de la oposición de las comunidades mapuchepehuenche, para entonces ya se encontraban en funcionamiento. ${ }^{29}$

\section{Quiebre en la bahía: "vendidos" y "defensores"}

La fortaleza de la defensa del mar radicaba en su configuración micropolítica y territorializada, desde la cual se confrontaba el patrón de "acumulación por contaminación" asociado a la amenaza de evacuación de desechos industriales en el mar. ${ }^{30}$ Lo anterior fue comprendido por ARAUCO que asesorándose en figuras

28 Martín Correa y Eduardo Mella, Las razones del illkun/enojo. Memoria, despojo y criminalización en el territorio mapuche de Malleco, Santiago de Chile, LOM Ediciones, 2010, 240255; Pairican, op. cit., 267-304.

${ }^{29}$ Domingo Namuncura, Ralco: ¿represa o pobreza?, Santiago de Chile, LOM Ediciones, 1999.

${ }^{30}$ Guerra, Debbie y Juan Carlos Skewes, “Acumulación por desposesión y respuestas locales en el remodelaje de los paisajes estuariales del sur de Chile". Chungará, Revista de Antropología Chilena 42: 2, 2010, 451-463. 
políticas vinculadas a la Concertación, ${ }^{31}$ planificó intervenir las alianzas entre pescadores artesanales y mapuche-lafkenche.

La contrainsurgencia se justificó en la Responsabilidad Social Empresarial (RSE) y comenzó a operar con la cooptación de Joaquín Vargas, dirigente de los sindicatos de pescadores artesanales que integraban el comité. Con Vargas como intermediario, ARAUCO intervino los sindicatos y selló con éstos un pacto denominado "Convenio de Colaboración y Asistencia Recíproca". Convenio en que a cambio de la desmovilización y colaboración de los sindicatos en las labores que requiriera la empresa para construir el ducto al mar, ésta pagaría aproximadamente trescientos setenta y seis mil millones de pesos chilenos (aproximadamente setecientos cincuenta mil dólares). Dinero que sería desembolsado en las distintas fases de ejecución del proyecto: formulación de estudios, construcción y funcionamiento del ducto. No obstante a la cantidad anterior se sumaba el pago, por diez años a cada familia, de dos ingresos mínimos mensuales. ${ }^{32}$

Un integrante de los sindicatos que suscribió el convenio y que previo a las negociaciones participaba en la defensa del mar, relata cómo se realizaron los acuerdos:

Estaba trabajando en las salmoneras en el sur y en una salida que tuve, Joaquín Vargas ya estaba conversando con la celulosa, de espaldas a los sindicatos. Joaquín una vez presentó la propuesta y toda la gente le dijo que no. Después me volví a trabajar a las salmoneras y de repente me llamó mi señora para que retire mi cheque, que todos los sindicatos se habían vendido, que faltaba yo y pocos más que estábamos en el sur. Así que como estaban todos vendidos yo me vine a Mehuín y no me quedaba otra que recibir la plata. ${ }^{33}$

Por qué los pescadores transaron su oposición a ARAUCO a cambio de dinero, es una interrogante compleja de responder. Sin embargo, a partir del

\footnotetext{
${ }^{31}$ Me refiero a Eugenio Tironi, ex-asesor comunicacional de la concertación en la campaña del NO para derrocar a Pinochet. Su colaboración a ARAUCO la efectuó mediante la consultora Tironi Asociados. Otro asesor de Arauco fue Juan de Dios Parra, militante del Partido Socialista y secretario general de la Asociación Latinoamericana de Derechos Humanos (ALDHU), con sede en Ecuador.

32 ARAUCO, Convenio de Colaboración y Asistencia Recíproca, Valdivia, 09 de octubre 2007.

33 P.S. Entrevista con el autor, 13 de febrero, 2014.
} 
conocimiento que tenemos de la realidad local, pensamos que fueron principalmente tres los aspectos que incidieron. En primer lugar, el carácter jerárquico de la organización interna de los sindicatos, lo cual hizo que la cooptación de sus dirigentes produjera un efecto de desmovilización en cadena y descendente, desde sus directivas hacia las bases, como se expresa en el testimonio anterior. Segundo, la mayor articulación y dependencia hacia el mercado y el dinero, por parte de las familias de los pescadores artesanales que se encontraban agrupados en los sindicatos; lo cual contrasta con cierto grado de autosuficiencia económica de las comunidades mapuche. ${ }^{34}$ Por último y tal vez el aspecto más significativo y determinante, fue la fragilidad del arraigo de los pescadores artesanales con el territorio costero $\mathrm{y}$, de modo específico, la predominancia en éstos de una concepción del mar como fuente de extracción de recursos económicos. Como sostuvo en una oportunidad un pescador que integra los sindicatos: "cuando yo voy al mar, salgo a bucear y veo los erizos, los locos, las jaibas, lo primero que veo es plata". ${ }^{35}$

El convenio entre los sindicatos y ARAUCO que se hace público en octubre del 2007, marcó el quiebre del entramado social-comunitario que sustentaba la defensa del mar, al descolgarse del comité uno de los bloques importantes que lo conformaban. Desde entonces los mapuche-lafkenche que desde inicios del conflicto integraban la defensa, toman el control y protagonismo del comité y liderarán la resistencia contra el ducto. Así, la defensa del mar transitará de un entramado social-comunitario intercultural que resguardaba el territorio costero en tanto fuente de trabajo, sustento productivo e identidad territorial mapuche, a una recomposición liderada por las comunidades que enmarcarán el conflicto en la reivindicación por autonomía y recuperación territorial de espacios acuáticos frente al Estado y el capital extractivo. El protagonismo que adquieren algunas comunidades no excluirá a otras familias de pescadores que rechazaron el acuerdo con ARAUCO, pues algunas de éstas continuarán participando en el comité o

\footnotetext{
34 En los meses previos a que se firmara el contrato entre ARAUCO y los sindicatos, varias personas que participaban en éstos habían contraído créditos bancarios y para entonces se encontraban endeudadas. Estos créditos fueron ofrecidos directamente por ejecutivos bancarios que visitaron Mehuín. No sabemos qué relación directa o colusión pudo existir entre la oferta de éstos créditos a los pescadores artesanales y la estrategia de división impulsada por Arauco, pero sin duda el endeudamiento contribuyó a que varias familias adhirieran al convenio.

35 P.S., op. cit.
} 
colaborando indirectamente en la defensa del mar. Incluso con el correr del tiempo, hubo pescadores que habiendo recibido dinero de la empresa pusieron a disposición de la defensa del mar una parte de éste, mientras que también desde el año 2010 hubo algunas familias mapuche que aceptaron el dinero de ARAUCO a cambio de su desmovilización.

Frente a este nuevo escenario y como el control del territorio continuaba siendo crucial para los defensores del mar, una de las primeras acciones implementadas por éstos fue el bloqueo estratégico del acceso a la bahía para impedir nuevos estudios de batimetría, en los que también colaborarían los sindicatos alineados con la empresa. Sin embargo, presionados por esta última, la que nuevamente se encontraba obstaculizada de efectuar las mediciones requeridas para formular el Estudio de Impacto Ambiental; suspendida la entrega de dinero a los sindicatos debido a que los pagos se supeditaban al avance de las obras; y finalmente, impedidos de ingresar mar adentro para dedicarse a sus labores diarias de pesca y buceo, los pescadores agrupados en los sindicatos se volcaron en un espiral de violencia, amedrentamientos y amenazas de muerte contra los opositores al ducto. Estos hechos tuvieron como punto álgido un ataque masivo efectuado a inicios de abril de 2006 contra la sede de los defensores del mar en la desembocadura del rio Lingue, donde se encontraban en su mayoría mujeres que fueron apedreadas.

A esta agresión siguieron una serie de amenazas de muerte y acciones de amedrentamiento. Así, al quiebre del tejido social siguió la violencia y el deterioro de las relaciones sociales al interior del territorio y las propias familias:

Ahora hay una división enorme. Incluso entre las familias, entre los matrimonios, entre padres e hijos. Ya no se va a la casa de una hija, si su marido se ha vendido. El conflicto se trata también de los sentimientos. Uno como familia se desarma entera. Nos sentimos dolidas. Desuniones en las familias, con las hijas. Antes que pasara el conflicto éramos uno solo, una familia. ${ }^{36}$

Los niños y niñas que crecieron en este contexto, también fueron víctimas de la violencia inducida por ARAUCO y vehiculizada por los sindicatos de pescadores como vía de desmovilización social. Niños y niñas comenzaron a proyectar su vivencia del conflicto a través de juegos que recreaban

\footnotetext{
${ }^{36}$ N.P. Entrevista con el autor, 15 de agosto, 2008.
} 
enfrentamientos entre "vendidos" y "defensores", a la vez que mediante sentimientos de angustia, temor y agresividad. Una niña mapuche en ese entonces relataba que:

Una de las cosas que más me da miedo es ir a la sede, me da temor hasta pasar por ahí, ahí donde está la cancha... después cuando vi que la apedrearon, yo vi cuando vinieron y le tiraron piedras a la sede y después no se me ha pasado el miedo cada vez que alguien va para allá, que pase algo de nuevo, que la ataquen otra vez, que CELCO para hacer sus estudios mande gente a atacar la sede... me da miedo andar sola, o quedarme sola, porque nos apedrearon la casa, y ahora como han amenazado tanto, me da miedo que quemen mi casa. ${ }^{37}$

Por otra parte, debido a que las personas que negociaron con la empresa pertenecían, preferentemente, a familias que se auto-reconocen como chilenos y quienes se mantuvieron en la defensa del mar fueron principalmente algunas comunidades mapuche-lafkenche, la polarización social y la violencia acrecentó y radicalizó una frontera entre ambos sectores bajo la forma de un conflicto que opuso a los "vendidos" con los "defensores" o "indios". 38 Numerosos acontecimientos de violencia física fueron denunciados a la justicia chilena, pero no fueron acogidos a tramitación o se archivaron tempranamente. Por otra parte, las autoridades de gobierno se desmarcaron de la cadena de acciones violentas que produjeron las negociaciones entre ARAUCO y los sindicatos, argumentando que se trataba de "un conflicto entre privados". ${ }^{39}$ Sin embargo, en paralelo actualizaron el discurso racista decimonónico que buscaba instalar en la opinión pública la imagen de los mapuche como obstáculos del desarrollo y el crecimiento económico.

Que las autoridades políticas chilenas se hayan desmarcado de las acciones de violencia contra los opositores al ducto, sosteniendo que al tratarse de un "conflicto entre privados" no podían intervenir, expresa cómo el extractivismo neoliberal opera mediante la (des)regulación diferenciada de espacios y sujetos. En

\footnotetext{
${ }^{37}$ Citado por Claudia Molina, Informe pericial: Daño psicológico evaluado en niños residentes en la comunidad de Misisipi asociado a la intervención de la empresa CELCO, Valdivia, 2009.

$38 \mathrm{Si}$ bien quienes se han mantenido vinculados a la defensa del mar han sido los mapuchelafkenche, importa destacar que desde el año 2010 algunas familias mapuche que han establecido relaciones económicas con ARAUCO.

${ }^{39}$ Diario Austral de Valdivia, "No hay ningún conflicto que mediar", 21 de octubre de 2007.
} 
efecto, en Chile como en otros países de América Latina, las nuevas formas de despojo sobre territorios indígenas requieren de un permanente estado de excepción de facto que se manifiesta en el ejercicio de la violencia y la criminalización para efectos de vaciar territorios y promover su inserción en circuitos económicos globales. ${ }^{40} \mathrm{En}$ el caso de las empresas forestales, entre ellas ARAUCO, han sido protagonistas de la criminalización de las movilizaciones mapuche que afectan sus inversiones. Entre otros efectos, esta criminalización se ha expresado en la tipificación de acciones de resistencia como delitos, conllevando a procesos judiciales que han concluido en el encarcelamiento de mapuche. En estos procesos el Estado no sólo ha utilizado delitos comunes establecidos en el código penal para incriminar, también leyes de excepción como la ley antiterrorista o la ley de seguridad interior del Estado para agravar penas y suprimir garantías procesales. ${ }^{41}$ En este sentido, lo que se juega en el conflicto en la bahía de Mehuín es algo más que los impactos ambientales que produciría la evacuación de residuos industriales. Sino ante todo la reproducción de un patrón histórico de "despojo racializado" 42 sobre territorio mapuche, el uso diferenciado de la violencia y la criminalización contra el "indio" como medio de control o escarmiento, así como la integración del Estado en las relaciones capitalistas.

De esta forma -y regresando a la reconstrucción histórica de los acontecimientos- el año 2010, luego que la empresa finalmente presentara ante COREMA un Estudio de Impacto Ambiental, éste fue aprobado durante los últimos días del primer gobierno de Michelle Bachelet. En este escenario, los defensores del mar reforzaron otras estrategias que, en lo sustantivo, complementaron el control territorial con la articulación de alianzas con organizaciones mapuche y pescadores artesanales de otros territorios costeros. Lo anterior, sobre la base de un intenso trabajo político de fortalecimiento del entramado social-comunitario, mediante la centralidad que otorgaron a la memoria histórica como recurso de cohesión y resistencia territorializada.

\footnotetext{
40 Zibechi, Raúl, "El estado de excepción como paradigma político del extractivismo", Claudia Composto y Mina Lorena Navarro (eds.), Territorios en disputa. Despojo capitalista, luchas en defensa de los bienes comunes naturales y alternativas emancipatorias para América Latina, México, Bajo Tierra Ediciones, 2014, 76-88.

${ }^{41}$ Aylwin, op. cit., 18-19.

42 Moore, Donald, Suffering for territory: race, place and power in Zimbabwe. Durham y Londres: Duke University Press, 2005, 129-152.
} 
Héctor Nahuelpan, Micropolíticas mapuche contra el despojo en el Chile neoliberal. La disputa por el lafkenmapu (territorio costero) en Mehuín, Izquierdas, 30, Octubre 2016: 89-123

Paralelamente, las comunidades comenzaron reconfigurar localmente derechos indígenas y los utilizaron en los intersticios del aparato burocrático del Estado para bloquear la tramitación de autorizaciones que ARAUCO requiere para concretar su proyecto. ${ }^{43}$

\section{La micropolítica mapuche y sus estrategias}

El conflicto en Mehuín ha transcurrido durante la mayor parte del ciclo democrático neoliberal, extendiéndose desde el año 1996 hasta la actualidad. Cabe preguntarnos entonces ¿por qué la construcción del ducto de evacuación de residuos industriales al mar no se ha concretado? La respuesta a esta interrogante no la encontramos en el actuar de los consecutivos gobiernos civiles que, por el contrario, han propiciado la integración de los territorios mapuche en redes trasnacionales de inversión, producción y comercialización de recursos rentables dentro de la economía mundial, dando continuidad al modelo primarioexportador que ha caracterizado históricamente la economía chilena ${ }^{44}$ y al patrón de despojo colonial impuesto sobre territorio mapuche en el siglo XIX.45 En este escenario, el principal obstáculo que ha tenido ARAUCO ha sido la capacidad de auto-organización cotidiana de la defensa y resistencia local, específicamente, el carácter micropolítico en que se sustenta. ${ }^{46}$

\footnotetext{
${ }^{43}$ Cuadra, Ximena, "Nuevas estrategias de los movimientos indígenas contra el extractivismo en Chile". Revista CIDOB d'Afers Internacionals 105, 2014, 141-163.

${ }^{44}$ Gabriel Salazar y Julio Pinto, Historia contemporánea de Chile III. La economía: mercados, empresarios y trabajadores, Santiago de Chile, LOM Ediciones, 2002, 11-14.

${ }^{45}$ Nahuelpán, Héctor, "Formación colonial del Estado y desposesión en Ngulumapu". Héctor Nahuelpan (ed.), Ta iñ fijke xipa rakizuameluwün. Historia, colonialismo y resistencia desde el País Mapuche, Temuco, Ediciones Comunidad de Historia Mapuche, 2012, 123-156.

${ }^{46} \mathrm{Si}$ bien existen otros factores que han incidido en que el ducto al mar no se concrete (como los cambios en el vertido de desechos al río cruces, la colaboración de personas y organizaciones defensoras de derechos humanos o estándares internacionales que presionan a las empresas a evitar conflictos), pensamos que al igual que en otros contexto de resistencia al extractivismo durante la actual fase de globalización neoliberal, ha sido la capacidad de articulación y organización de la población local la pieza clave de la defensa del mar. Como sostiene Jameson, la potencia de toda forma de resistencia deriva siempre de su anclaje en una comunidad realmente existente, pues "las formas preexistentes de cohesión social, aunque no son suficientes por sí mismas, constituyen necesariamente la condición previa indispensable de toda lucha eficaz y duradera, de todo gran empeño colectivo. Al mismo tiempo estas formas de cohesión son de suyo el contenido de la lucha,
} 
El proceso de auto-organización y auto-defensa de las comunidades encuentra su soporte en la acción micropolítica, situando la cotidianeidad como espacio estratégico para confrontar la penetración del capital en el territorio y las relaciones sociales. Asimismo, ha articulado una diversidad de actores locales que convergen en la construcción del territorio costero como espacio de defensa y lucha, poniendo en juego, si fuese necesario, la vida humana a favor de la reproducción social y cultural. Esta micropolítica que no apuesta por la toma del poder estatal o de sus instituciones como eje de cambio social, sino por la transformación desde abajo, se nutrió de diversos conocimientos e historias que los actores locales socializan en los espacios de auto-organización, contribuyendo al fortalecimiento de identidades territorializadas. En esta micropolítica la autoorganización y auto-defensa han demostrado flexibilidad para reacomodarse a las distintas coyunturas del conflicto, como también capacidad de resilencia frente a las intervenciones y quiebres que ha generado la empresa, asumiendo que la principal fortaleza del movimiento ha radicado en los vínculos sociales creados, la complementariedad de estrategias, así como la vigilancia e intervención en los procesos de tramitación burocráticos que lleva ARAUCO para concretar su proyecto.

Otro rasgo que caracteriza esta micropolítica, en particular luego de que los mapuche-lafkenche asumen como actores centrales en el conflicto, radica en que cuando se moviliza públicamente combina distintas estrategias de acción: contra el Estado, dentro del Estado, fuera del Estado y contra el capital-empresa. Estas estrategias no se despliegan de modo excluyente, sino de forma simultánea como ocurre en otros contextos de acción política indígena en América Latina. ${ }^{47}$ Asimismo, los límites entre estas estrategias son difusos y sólo teóricamente podemos establecer distinciones, pues como bien sabemos los grupos subalternos y

\footnotetext{
los envites de todo movimiento político, el programa por así decir de su propio proyecto". Fredric Jameson, “Globalización y estrategia política”, New Left Review 5, 2000, 5-22.

47 Aracely Burguete, "Gobernar en la diversidad en tiempos de multiculturalismo en América Latina”, Xochitl Leyva, Shannon Speed y Aracely Burguete (eds.), Gobernar en la diversidad: experiencias indígenas desde América Latina. Hacia la investigación de co-labor, México, CIESAS / FLACSO, 2008, 15-64.
} 
sus acciones también se modelan en el terreno del Estado y no en un ámbito exclusivamente externo. 48

La estrategia de ir contra el Estado se relaciona con la forma en que el conflicto como espacio de aprendizaje, ha contribuido a que los mapuche perciban que el lugar que ocupan dentro del Estado se ha instaurado mediante acciones de fuerza y violencia que explican la reproducción de patrones históricos de despojo y desigualdad. En palabras de una lamgen (hermana):

Como que siempre el mapuche ha vivido en la defensa, bueno de repente como que vive feliz y tranquilo, pero como que siempre ha vivido en la defensa, que otras personas te puedan quitar todo lo que tienes, el territorio, tierra y todo, y el Estado siempre a favor de los que amenazan. Entonces si antiguamente se defendió, ¿cómo no lo vamos a defender nosotras?, si nos entregaron este territorio libre, limpio, ¿por qué nosotras vamos a hacer lo contrario?, tenemos que seguir, y así entregárselo a los que vienen porque una pasa y después vienen nuestros hijos. Si tú vez toda la historia, siempre ha sido una defensa que hemos tenido en todos los tiempos, entonces ipor qué no ahora?49

Desde las perspectivas locales, el conflicto actual es parte de un continuum histórico de injusticias y la resistencia como expresión reivindicativa de una autonomía truncada por la colonización. En este sentido, el antagonismo también produjo la apertura de diversos espacios de diálogo donde las memorias de los despojos de tierras a inicios del siglo XX y la circulación de historias previas de autonomía política y territorial, proporcionaron nuevos marcos interpretativos sobre el pasado y el presente. Estos marcos interpretativos comenzaron a situar al campo jurídico y burocrático estatal en el centro de la reproducción de la desigualdad y el despojo, lo que a nivel práctico se tradujo en la definición del control territorial como aspecto crucial de la resistencia, la confrontación con las fuerzas represivas cuando se han pretendido realizar estudios en tierra y mar, así como el desacato a las resoluciones administrativas que concedían los permisos requeridos para que la empresa construya el ducto.

\footnotetext{
48 Antonio Gramsci, Cuadernos de la cárcel, Tomo 6, México, Ediciones Era, 2000, 176-177; Mitchell, Timothy, "The Limits of the State: Beyond Statist Approaches and Their Critics". The American Political Science Review 85:1, 1991, 93.

${ }^{49}$ Rosa Nahuelpán, entrevista con el autor, 14 de abril, 2011.
} 
No obstante lo anterior, para los defensores del mar ir contra el Estado también debía complementarse con el uso estratégico de los intersticios que se abren dentro del propio aparato estatal para obstaculizar la construcción del ducto. Por ello moverse dentro del Estado también fue transformándose en otra de las estrategias coyunturalmente viables para evitar la criminalización de la resistencia. Proceso que lejos de permitir una correlación de fuerzas a favor de los mapuche, propiciaría su desgaste, como advierte uno de los opositores al ducto:

A todos estos años la empresa no ha movido una sola máquina para construir su ducto y hasta ahora no tenemos ningún peñi acusado de terrorista. $\mathrm{Y}$ en eso ha tenido mucho que ver que nosotros hemos sabido movernos en el terreno del sistema, del enemigo, pero siempre como instrumento. Porque si en algún momento eso no funciona, tenemos que resistir de otra forma. ${ }^{50}$

El testimonio anterior puede comprenderse mejor si se considera que durante el "retorno a la democracia" el poder punitivo -esa última ratio de un Estado- pasó a ser prima ratio para manejar la movilización mapuche. ${ }^{51}$ En otras palabras, la principal respuesta de los gobiernos democráticos a las reivindicaciones territoriales durante la democracia neoliberal, ha sido la represión y criminalización de las demandas por autonomía para resguardar los privilegios de los descendientes de colonos que poseen las tierras mapuche usurpadas, los intereses de grupos económicos nacionales y trasnacionales, el "orden público" y la "seguridad nacional". 52

En este sentido, la estrategia de moverse dentro del Estado ha implicado usar creativamente los espacios permitidos, como son las "comunidades indígenas". Cabe recordar que éstas y las "asociaciones indígenas", fueron creadas por la ley $\mathrm{n}^{\circ} 19.253$ promulgada en 1993 para canalizar la política estatal y programas asistenciales que recrean vínculos de dependencia de los mapuche con los organismos de Estado. "Comunidades" y "asociaciones" son los espacios de

\footnotetext{
${ }^{50}$ F.G. Entrevista con el autor, 15 de diciembre, 2013.

51 Victor Toledo, "Prima ratio. Movilización mapuche y política penal: los marcos de la política indígena en Chile, 2000-2007", OSAL 22, 2007, 253-275.

52 Eduardo Mella, Los mapuches ante la justicia. Criminalización y protesta indígena en Chile, Santiago de Chile, LOM Ediciones, 2007.
} 
organización tolerados, por lo que una forma alternativa o paralela que pueda crearse en una zona de conflicto arriesga ser tipificada como "asociación ilícita", como ha sucedido en otras ocasiones donde el Estado ejerce su poder punitivo. En términos analíticos, esta estrategia de uso creativo de los espacios permitidos, expresa como las políticas implementadas en el contexto del multiculturalismo neoliberal a la chilena, ${ }^{53}$ también son contestadas, negociadas o reconfiguradas desde abajo y canalizadas hacia otras direcciones por los mapuche.

El uso de las comunidades indígenas como ámbitos de articulación, desde el año 2009 comenzó a complementarse con la conformación de una asociación de comunidades que agrupó a catorce de éstas para ejercer la ley que el año 2008 creó los Espacios Costeros Marinos de los Pueblos Originarios (ECMPO). La relevancia de esta ley radicaba no sólo en la posibilidad de crear una forma de organización amplia que articule varias comunidades evitando su definición como "asociación ilícita", sino que el ejercicio de la ley por los mapuche-lafkenche se tradujo en un serio obstáculo para ARAUCO y el Estado. En efecto, esta legislación se origina en los impactos que la extracción industrial de recursos pesqueros estaba teniendo para las comunidades mapuche-lafkenche, en particular desde 1991 cuando se promulgó la ley general de pesca y acuicultura. En respuesta a ello, el año siguiente se formó la organización Identidad Territorial Lafkenche (ITL) que reúne a mapuche de territorios costeros de las regiones del Bio Bio, Araucanía, Los Ríos, Los Lagos y Aysen. Desde el año 2002 la ITL desarrolló un proceso de debate interno, surgiendo la idea de crear una ley para ejercer el derecho mapuche al lafkenmapu. De los diversos encuentros emergió "desde abajo" la propuesta de ley que luego de ser negociada con representantes del gobierno de Ricardo Lagos y del bloque opositor en el parlamento, se promulgó el año 2008.54 De allí precisamente que este cuerpo jurídico sea conocido como "ley lafkenche", pues reconoce el "uso consuetudinario" que las comunidades indígenas han ejercido en el borde costero, permitiendo que las mismas o asociaciones de comunidades administren espacios

\footnotetext{
${ }^{53}$ Charles R. Hale y Rosamel Millamán, "Cultural agency and political strugggle in the Era of the Indio Permitido", Doris Sommer (ed.), Cultural Agency in the Americas, Durham y Londres, Duke University Press, 2006, 281-304; Patricia Richards, Race and the chilean miracle: neoliberalism, democracy, and indigenous rights, Pittsburgh, University of Pittsburgh Press, 2013.

${ }^{54}$ Susana Huenul, "Construcción sociopolítica de la 'Ley Lafkenche'”, Héctor Nahuelpan (ed.), Ta iñ fijke xipa rakizuameluwün. Historia, colonialismo y resistencia desde el País Mapuche, Temuco, Ediciones Comunidad de Historia Mapuche, 2012, 215-239.
} 
y practiquen actividades productivas, recreativas, medicinales, religiosas, previa solicitud de los ECMPO y aprobación por parte de organismos de Estado.

Unos meses después de promulgada la ley que creó los ECMPO, las primeras solicitudes puestas a tramitación fueron las de opositores al ducto en Mehuín, quienes se agruparon en la Asociación de Comunidades Mapuche Lafkenche de Mariquina. Que las primeras tramitaciones emergieran desde Mehuín no fue fortuito. Varios de los líderes de la zona habían participado en la formulación de la propuesta de ley dentro de la ITL, en los debates y negociaciones con el gobierno de Ricardo Lagos, diputados y senadores de centro-izquierda y derecha: "conocíamos la ley, conocíamos el Estado y estábamos en conflicto". ${ }^{55}$ Estos líderes percibieron la creación de la ley no sólo como una forma de reconocer "usos consuetudinarios", sino como instrumento cuya utilización estratégica contribuiría a la defensa del mar frente a la arremetida del capital extractivo. En particular porque la citada normativa al establecer que si una comunidad o asociación de éstas solicita un ECMPO se suspende cualquier otra tramitación sobre el mismo espacio, hizo que la concesión marítima requerida por ARAUCO para construir el ducto al mar se paralice desde el año 2009 hasta la actualidad.

Por otra parte, aquellas estrategias que se desarrollan fuera del Estado, pero que también se dirigen contra éste o hacen uso de normativas internacionales reconocidas, pueden identificarse fundamentalmente dos ámbitos de acción. El primero corresponde a la reconfiguración local de cuerpos jurídicos internacionales que reconocen derechos indígenas -como el Convenio 169 de la OIT o la Declaración ONU sobre Derechos de los Pueblos Indígenas- para denunciar en el ámbito internacional las violaciones a los derechos humanos mapuche causadas en el marco del conflicto, y para legitimar frente al Estado y la sociedad civil la defensa y resistencia. Como sostiene uno de los defensores del mar:

Nosotros sabemos que más allá de estos derechos nuestra defensa es legítima, pero tenemos que usar esos instrumentos. Por eso cuando nos paramos frente al sistema, con el Estado, les decimos "respeten el Estado de derecho que tanto hablan, nosotros lo estamos respetando, porque nos amparamos en los derechos que ustedes firmaron". Hacemos una utilización

\footnotetext{
${ }^{55}$ Hualme, op. cit.
} 
estratégica de estas leyes internacionales para resguardarnos y enfrentar al Estado y la empresa que son como dos caras de la misma moneda. ${ }^{56}$

En segundo lugar, en esta acción "fuera del Estado" se ubican además los espacios de auto-organización. Estos espacios corresponden a los trawün (juntas, asambleas) donde se recrea una práctica política mapuche que involucra dialogo, deliberación y acuerdo para planificar estrategias y evaluar sus alcances. Aquí el recurso a la memoria es uno de los aspectos más significativos que se ponen en juego, pues la dinámica de deliberación política está acompañada de diálogos intergeneracionales que contribuyen al reforzamiento de los vínculos sociales y culturales que soportan la defensa del mar. Al respecto, cito las palabras de un joven dirigente que participa de los trawün:

Yo creo que reunirnos ha sido importante. Antes del conflicto alguna gente se juntaba para ir al ngillatun o sólo para las reuniones con la CONADI. Pero ahora nos hemos reunido por otras cosas, nos auto-convocamos, discutimos entre nosotros porque no siempre estamos de acuerdo en todo, pero veo más fortaleza dentro de mi misma gente y dentro de eso creo que me ha servido bastante conocer mi historia. 57

Por último, aquellas estrategias que se movilizan contra, como dentro o fuera del Estado, sólo adquieren sentido si impiden la construcción del ducto, es decir, en tanto confrontan el capital-empresa. Esto es así porque en contraste con otros conflictos donde los actores en disputa pueden llegar a acuerdos transando posiciones, los defensores del mar no buscan negociar con ARAUCO $u$ obtener compensaciones económicas a cambio de la contaminación del mar y el despojo de su principal fuente de vida:

Para nosotros no hay negociación posible, es "no al ducto" y punto. Aquí hay un problema territorial grande, son las mismas trasnacionales que también están en la tierra, como las forestales. Entonces teniendo claro eso, la invasión a través de estas transnacionales que están en el mar, en la tierra, en todo el territorio, la conciencia política y la claridad es que uno debe dar la

\footnotetext{
56 B.A. Entrevista con el autor, 13 de julio, 2014.

${ }^{57}$ Javier Nahuelpán, entrevista con el autor, 6 de abril, 2011.
} 
lucha, dar la pelea por recuperar este territorio que es el mar o mantener el territorio sin contaminación y mantenerlo siempre. Eso no lo transamos. ${ }^{58}$

\section{Conclusiones: la irrupción de nuevas identidades políticas mapuche}

El conflicto por el lafkenmapu en Mehuín vino a remecer y a reconfigurar relaciones sociales, abonando el terreno para la irrupción de subjetividades e identidades políticas mapuche que en el transcurso de la lucha contra el despojo y la contaminación que produce el capitalismo extractivo, vienen a interrogar y a desafiar la reproducción del racismo estructural. ${ }^{59}$ Esto ha sido así porque la confrontación con ARAUCO marca una inflexión en la historia local, abriendo espacios de encuentro y diálogo intergeneracional al interior de las familias, comunidades y lugares donde se organizan. Estas relaciones y diálogos a su vez han producido nuevos marcos interpretativos sobre la vida presente y pasada, las trayectorias de las personas y familias, a la vez que sobre las experiencias de discriminación y desigualdad histórica. Por ello cuando hoy en día los jóvenes dialogan y contrastan sus experiencias con las de generaciones previas, precisan que a diferencia de la mimetización con que éstas enfrentaron la discriminación racial con anterioridad al conflicto, en las nuevas generaciones ha emergido mayor dignidad, fortaleza y voluntad por recuperar y reafirmar repertorios culturales mapuche racial e históricamente estigmatizados.

De igual forma, estos actores reconocen que la identidad mapuche se experiencia de formas diversas, afirmando que la fortaleza de la resistencia ha radicado precisamente en la capacidad de construir solidaridades desde sus diferentes trayectorias de vida. Como parte de este proceso, estas identidades heterogéneas también han reconstruido una concepción ontológica del lafkenmapu (territorio costero) como vida no-humana que junto con proveerles de recursos marinos para la supervivencia, también nutre los sentidos de identidad colectiva.

\footnotetext{
${ }^{58}$ L.LL. Entrevista con el autor, 6 de septiembre de 2014.

${ }^{59}$ Los espacios de antagonismo producen condiciones inestables en la vida social, permitiendo que las relaciones sociales se vuelvan maleables y susceptibles de adquirir nuevas formas. Por ende, que surjan nuevas subjetividades y se reconstruyan identidades. Al respecto véase: Gutierrez, Raquel, "Sobre la autoregulación social: imágenes, posibilidades y límites", Jóvenes en Resistencia Alternativa (Eds.), Pensar las autonomías. Alternativas de emancipación al capital y el estado, México, Sisífo Ediciones / Bajo Tierra Ediciones, 2010, 353.
} 
En otras palabras, esta irrupción de identidades políticas mapuche gestada en el transcurso del proceso de defensa del mar, no solo ha activado y movilizado "ontologías políticas" para resistir el capitalismo extractivo. ${ }^{60}$ Junto a ello está confrontando algunos dualismos constitutivos de la modernidad (naturaleza / cultura, moderno / tradicional, civilizado / bárbaro) que han subyacido a prácticas coloniales y neocoloniales de apropiación y violencia sobre territorio mapuche y de mercantilización de la vida en sus múltiples formas.

Lo anterior puede comprenderse al explicar sucintamente el significado de la noción mapu-che que, en contraste con la reducción interpretativa como "gente de la tierra", define un vínculo recíproco entre mapu entendido como espacio ultraterrenal (cosmos), terrenal (tierras, aguas, subsuelo) y che (persona). ${ }^{61} \mathrm{La}$ relación mapu-che se expresa, entre otros aspectos, en la pertenencia de vidas humanas a un determinado territorio (tuwün). Por ello la categoría lafken-che (gente del mar) designa el vínculo entre la persona (che) y un territorio acuático (lafkenmapu) que en el caso de Mehuín corresponde al mar y estuario del río Lingue. De esta forma, el vínculo entre el territorio acuático (lafkenmapu) y la persona (che) no se reduce al ámbito productivo. Por el contrario, en tanto el lafkenmapu es un organismo vivo -que a la vez congrega otras vidas (itro fill lafken mongen)-, el enraizamiento y las múltiples relaciones (materiales y simbólicas) que las personas establecen con éste, se encuentra normado por el az mapu (códigos de ética o normas). Este último se transmite familiar a intergeneracionalmente, entre otras vías, mediante la memoria mapuche (tukulpazugun).

Este trasfondo explica el sentido profundo que tiene para los mapuche la resistencia contra la contaminación del lafkenmapu en Mehuín. Pero igualmente devela el antagonismo y disputa entre, por una parte, una ontología fundada en la dicotomía naturaleza/cultura que concibe el mar como basurero para evacuar desechos tóxicos que permitan aumentar la producción de celulosa. Y, por otra, la

\footnotetext{
${ }^{60} \mathrm{Al}$ respecto véase: Mario Blaser, "La ontología política de un programa de caza sustentable". Red de Antropologías del Mundo 4, 2009, 81-107; Marisol De la Cadena, "Política indígena: un análisis más allá de 'la política'", Red de Antropologías del Mundo 4, 2009, 139-171; Arturo Escobar, "Latin America at a crossroads. Alternative modernizations, post-liberalism, or post-development?", Cultural Studies 24:1, 2010, 1-65.

${ }^{61}$ Quidel, José, La idea de "Dios" y "Diablo" en el discurso ritual mapuche. Tesis de Magister en Antropología Social, Brasil, Universidade Estadual de Campinas, 2012, 27-29.
} 
reconstrucción en el terreno del conflicto de una concepción ontológica mapuche signada por un vínculo relacional y recíproco entre personas y territorio. En este sentido, no estamos hablando de la existencia de distintas percepciones sobre "la" naturaleza, sino de mundos de vida que se hallan en una interacción conflictiva producto de relaciones de poder inscritas en la historia global del capitalismo y del colonialismo.

Por otro lado, el proceso de organización y defensa generado durante casi dos décadas en Mehuín, demuestra que la irrupción de nuevas subjetividades e identidades políticas mapuche también está desafiando la cosificación, despolitización y desterritorialización de las identidades indígenas que promueve el proyecto cultural neoliberal. ${ }^{62}$ Este último que durante las últimas dos décadas y mediante políticas y programas de reconocimiento tenue a pueblos indígenas en Chile, incentiva o busca potenciar identidades que no interroguen o esfuercen por desmantelar la reproducción de la desigualdad racial en un contexto caracterizado por la creciente penetración del capital en nuevos territorios y relaciones sociales. ${ }^{63}$ Esta "política de la distracción" 64 , nueva forma de disciplinamiento y pacificación que apuesta a que sujetos y comunidades reproduzcan patrones de dependencia estado-céntricos, ha tenido como contraparte precisamente la emergencia de identidades políticas que se sitúan al margen de esta nueva forma de hegemonía, al movilizarse por lo que ha sido y continúa siendo el motor de la historia mapuche y de los pueblos indígenas: el territorio.

Como parte de la irrupción de estas nuevas identidades políticas, también ha emergido una concepción particular de autonomía que enfatiza en la importancia de su construcción cotidiana y desde abajo. Dicha concepción contrasta con las formuladas por algunas organizaciones indígenas que definen la autonomía como una meta a alcanzar, un punto de llegada o discuten

\footnotetext{
${ }^{62}$ Hale, op. cit.

${ }^{63}$ Adrienne, Roberts, "Privatizing social reproduction: The primitive accumulation of water in an era of neoliberalism", Antipode. A Radical Journal of Geography 40: 4, 2008, 535-560.

${ }^{64} \mathrm{La}$ idea de que las formas de dependencia estado-céntricas y el reconocimiento estatal de los pueblos indígenas, forman parte de una "política de la distracción" que en ocasión desvirtúa objetivos de fondo relacionados con la autodeterminación y soberanía indígena, ha sido desarrollada por Taiaiake Alfred (Mohawk). Al respecto véase: Taiaiake Alfred, "Being indigenous: resurgences against contemporary colonialism", Government and Opposition 40: 4, 2005, 597-602; Taiaiake Alfred, "Colonialism and state dependency", Journal of Aboriginal Health 5, 2009, 42-60.
} 
normativamente sus alcances, obviando o minimizando las experiencias y aprendizajes que se desarrollan desde las recuperaciones de tierras, las resistencias frente al capital extractivo o las micropolíticas de organización y autogestión que proliferan en espacios rurales o urbanos. ${ }^{65} \mathrm{El}$ énfasis en la construcción de la autonomía desde la cotidianeidad de la lucha por el territorio, se comprende a través de la noción de kisugünewün, esto es, la capacidad que un sujeto individual o colectivo tiene para auto-gobernarse y decidir la proyección de su vida, anclada en el control del territorio. Desde esta concepción, la construcción cotidiana y micropolítica de la autonomía no se limita al ámbito local, sino que prefigura su ejercicio más amplio a través de la articulación de redes de alianzas de autoorganización y auto-defensa. Pensamos que éste modelo de autonomía basado en la acción micropolítica y que sitúa la cotidianeidad como espacio estratégico de impugnación, corrosión y transformación de relaciones de poder y condiciones de opresión histórica, es el que actualmente está perfilándose con más fuerza no sólo en Mehuín. Sino también en otros espacios mapuche e indígenas donde se llevan adelante recuperaciones de tierras o defensas frente al capital extractivo. Por lo mismo, pensamos que ésta corriente autonómica y los procesos políticos locales que la impulsan, se transformarán en el principal escollo para el Estado y el capital no sólo por la radicalidad de sus planteamientos, sino también por su capacidad para producir nuevas subjetividades e identidades políticas.

En este sentido, y para finalizar, creemos que la concepción de autonomía desde la acción micropolítica es uno de los aprendizajes más importantes que han obtenido los defensores y defensoras del mar durante el conflicto. Esto porque mediante sus acciones cotidianas de defensa también han buscado construir relaciones sociales y políticas mapuche que rompan con las formas de organización centralizadas y jerárquicas. Formas de organización que emulan las lógicas estatales que despojan a las sociedades indígenas del control y gobierno sobre sus propias vidas y territorios, mientras contaminan y saquean sus recursos para insertarlos en circuitos globales de comercio e intercambio. Sin duda en el transitar de todos estos años son diversas las contradicciones que estos procesos han debido

\footnotetext{
${ }^{65}$ La concepción de la autonomía como una meta a alcanzar o punto de llegada, asociada a una definición normativa, se haya presente en la mayor parte de las propuestas políticas que públicamente han formulado organizaciones mapuche. Para un análisis de estas propuestas puede verse el trabajo de José Marimán, Autodeterminación. Ideas políticas mapuche en el albor del siglo XXI, Santiago de Chile, LOM Ediciones, 2012.
} 
enfrentar, al tiempo que la resistencia contra ARAUCO es una expresión de lucha localizada, pero no aislada de las que protagonizan otras comunidades y organizaciones mapuche, indígenas, afrodescendientes y campesinas en América Latina. No obstante, aún cuando esta experiencia intenta resolver una problemática local, nos enseña no sólo la importancia de transformar las relaciones de desigualdad desde las mismas relaciones sociales cotidianas y subalternas. Sino también la centralidad que tiene la memoria y la reconstrucción de los entramados sociales-comunitarios mapuche al momento de enfrentar la contaminación, cosificación y mercantilización del territorio.

¿Cuál es el desenlace que tendrá la disputa por el lafkenmapu en Mehuín?, ¿persistirá en el tiempo esta voluntad de reconstruir la autonomía truncada por una larga historia de colonización?, ¿esta construcción de autonomía desde las acciones micropolíticas, se articulará a otras experiencias mapuche que se desarrollan actualmente en Wallmapu impulsando un proceso más amplio de descolonización?, son algunas de las interrogantes abiertas y cuyas respuestas son inciertas. Sin embargo, lo que sí sabemos es que hasta entonces la resistencia de Mehuín representa una pulsión de vida contra el modelo de muerte que conlleva la profundización del despojo y el extractivismo en el Chile neoliberal. Y éste no es objetivo de poca monta.

\section{Bibliografía}

Alfred, Taiaiake, "Being indigenous: resurgences against contemporary colonialism", Government and Opposition 40: 4, 2005, 597-602.

Alfred, Taiaiake, "Colonialism and state dependency", Journal of Aboriginal Health 5, 2009, 42-60.

ARAUCO, Convenio de Colaboración y Asistencia Recíproca, Valdivia, 09 de octubre 2007.

ARAUCO, Memoria Anual 2011, Santiago de Chile, 2011.

Aylwin, José, Nancy Yáñez, y Rubén Sánchez, Pueblo mapuche y recursos forestales en Chile: devastación y conservación en un contexto de globalización económica, Santiago de Chile, IWGIA / Observatorio Ciudadano, 2013. 
Héctor Nahuelpan, Micropolíticas mapuche contra el despojo en el Chile neoliberal. La disputa por el lafkenmapu (territorio costero) en Mehuín, Izquierdas, 30, Octubre 2016: 89-123

Baschet, Jérome, "Punto de vista e investigación: el caso del zapatismo", Desacatos, 33, 2010, 189-201.

Blaser, Mario, "La ontología política de un programa de caza sustentable", Red de Antropologías del Mundo 4, 2009, 81-107.

Burguete, Aracely, "Gobernar en la diversidad en tiempos de multiculturalismo en América Latina", Xochitl Leyva, Shannon Speed y Aracely Burguete (eds.), Gobernar en la diversidad: experiencias indígenas desde América Latina. Hacia la investigación de colabor, México, CIESAS / FLACSO, 2008, 15-64.

Constitución Política de la República de Chile, Editorial Jurídica de Chile, Santiago, 1993.

Coordinadora de Comunidades Mapuche Lafkenche, Declaración pública, 20 de junio de 1996.

Correa, Martín y Eduardo Mella, Las razones del illkun/enojo. Memoria, despojo y criminalización en el territorio mapuche de Malleco, Santiago de Chile, LOM Ediciones, 2010.

Corvalán, Luis, Del anticapitalismo al neoliberalismo en Chile, Santiago de Chile, Editorial Sudamericana, 2001.

Cuadra, Ximena, "Nuevas estrategias de los movimientos indígenas contra el extractivismo en Chile". Revista CIDOB d'Afers Internacionals 105, 2014, 141-163.

De la Cadena, Marisol, "Política indígena: un análisis más allá de 'la política'”, Red de Antropologías del Mundo 4, 2009, 139-171.

Dhase, Fernando, Mapa de la extrema riqueza, Santiago de Chile, Aconcagua, 1979.

Diario Austral de Valdivia, "Es muy delicado oponerse por oponerse”, 23 de noviembre de 1996.

Diario Austral de Valdivia," "Programa se retoma siempre que exista el resguardo necesario", 13 de enero de 1998

Diario Austral de Valdivia," "No hay ningún conflicto que mediar", 21 de octubre de 2007.

Escobar, Arturo, "Latin America at a crossroads. Alternative modernizations, postliberalism, or post-development?", Cultural Studies 24:1, 2010, 1-65.

Falcon, Romana, México descalzo, México, Plaza y Janés, 2002.

Foucault, Michel, Microfísica del poder, Madrid, La Piqueta, 1991.

García, Julio, Ingrid Henríquez y Daniella Ramírez, "Caso CELCO: una falla multisistémica", Revista de Derecho Ambiental, 2, 2005, 141-166. 
Héctor Nahuelpan, Micropolíticas mapuche contra el despojo en el Chile neoliberal. La disputa por el lafkenmapu (territorio costero) en Mehuín, Izquierdas, 30, Octubre 2016: 89-123

Garreton, Manuel, Neoliberalismo corregido y progresismo limitado. Los gobiernos de la Concertación en Chile, 1990-2010, Santiago de Chile, Editorial ARCIS / CLACSO, 2012.

Gramsci, Antonio, Cuadernos de la cárcel, Tomo 6, México, Ediciones Era, 2000.

Guattari, Felix y Suely Rolnik, Micropolítica. Cartografías del deseo, Madrid, Traficantes de Sueños, 2006.

Guerra, Debbie y Juan Carlos Skewes, “Acumulación por desposesión y respuestas locales en el remodelaje de los paisajes estuariales del sur de Chile". Chungará, Revista de Antropología Chilena 42: 2, 2010, 451-463.

Gutierrez, Raquel, "Sobre la autoregulación social: imágenes, posibilidades y límites", Jóvenes en Resistencia Alternativa (Eds.), Pensar las autonomías. Alternativas de emancipación al capital y el estado, México, Sisífo Ediciones / Bajo Tierra Ediciones, 2010, 351-373.

Hale, Charles R., Does multiculturalism menace? Governance, cultural rights and the politics of identity in Guatemala, Journal of Latin American Studies 34: 3, 2002, 485-524.

Hale, Charles R. y Rosamel Millamán, "Cultural agency and political strugggle in the Era of the Indio Permitido", Doris Sommer (ed.), Cultural Agency in the Americas, Durham y Londres, Duke University Press, 2006, 281-304.

Haraway, Donna, Ciencia, cyborgs y mujeres. La reinvención de la naturaleza. Madrid, Catedra, 1995.

Harvey, David, El nuevo imperialismo, Madrid, Ediciones AKAL, 2004.

Hartsock, Nancy, “The feminist standpoint”, Sandra Harding y Merrill Hintikka (eds.), Discovering reality. Feminist perspectives on epistemology. Metaphysics, methodology and philosophy of science, Boston y Londres, D. Riedel Publishing Company, 1983, 283310.

Huenul, Susana, "Construcción sociopolítica de la 'Ley Lafkenche'", Héctor Nahuelpan (ed.), Ta iñ fijke xipa rakizuameluwün. Historia, colonialismo y resistencia desde el País Mapuche, Temuco, Ediciones Comunidad de Historia Mapuche, 2012, 215-239.

Jameson, Fredric, “Globalización y estrategia política”, New Left Review 5, 2000, 5-22.

Klubock, Thomas, La Frontera. Forest and ecological conflict in Chile's frontier territory, Durham, Duke University Press.

La Segunda, "Planta de celulosa Valdivia significa una verdadera explosión de desarrollo", 19 de marzo, 1997.

Luxemburgo, Rosa, La acumulación del capital, Barcelona, Ediciones Grijalbo, 1972. 
Héctor Nahuelpan, Micropolíticas mapuche contra el despojo en el Chile neoliberal. La disputa por el lafkenmapu (territorio costero) en Mehuín, Izquierdas, 30, Octubre 2016: 89-123

Llaitul, Hector y Jorge Arrate, Weychan. Conversaciones con un weychafe en la prisión política, CEIBO, Santiago de Chile, 2012.

Marimán, José, Autodeterminación. Ideas políticas mapuche en el albor del siglo XXI, Santiago de Chile, LOM Ediciones, 2012.

Mella, Eduardo, Los mapuches ante la justicia. Criminalización y protesta indígena en Chile, Santiago de Chile, LOM Ediciones, 2007.

Mitchell, Timothy, "The Limits of the State: Beyond Statist Approaches and Their Critics". The American Political Science Review 85:1, 1991, 77-96.

Molina, Claudia, Informe pericial: Daño psicológico evaluado en niños residentes en la comunidad de Misisipi asociado a la intervención de la empresa CELCO, Valdivia, 2009.

Moore, Donald, Suffering for territory: race, place and power in Zimbabwe. Durham y Londres: Duke University Press, 2005.

Morales, Bárbara, "Defensa del medioambiente y ciudadanía: etnografía de los procesos de construcción de comunidad en el curso de la acción colectiva. El caso del Comité de Defensa del Mar en la zona costera de Mehuín, Chile", Persona y Sociedad 27:2, 2013, 145167.

Nahuelpán, Héctor, “Formación colonial del Estado y desposesión en Ngulumapu”. Héctor Nahuelpan (ed.), Ta iñ fijke xipa rakizuameluwün. Historia, colonialismo y resistencia desde el País Mapuche, Temuco, Ediciones Comunidad de Historia Mapuche, 2012, 123-156.

Héctor Nahuelpan, " 'Nos explotaron como animales y ahora quieren que no nos levantemos'. Vidas despojables y micropolíticas de resistencia mapuche", Enrique Antileo, Herson Huinca y Luis Cárcamo-Huechante (Eds.), Awükan ka kuxankan zugu Wajmapu mew. Violencias coloniales en Wajmapu, Temuco, Ediciones Comunidad de Historia Mapuche, 2015, 271-300.

Namuncura, Domingo, Ralco: ¿represa o pobreza?, Santiago de Chile, LOM Ediciones, 1999.

Pairican, Fernando, Malón. La rebelión del movimiento mapuche, 1990-2013. Santiago de Chile, Pehuen Editores, 2014.

Pairican, Fernando y Rolando Alvarez, "La Nueva Guerra de Arauco: la Coordinadora Arauco Malleco y los nuevos movimientos de resistencia mapuche en el Chile de la Concertación (1997-2009)", Revista Izquierdas 10, 2011, 66-84

Palma, Karen, Desarrollo forestal en la Región de los Ríos. Análisis de la resistencia y el impacto en la comunidad Mapuche Lafkenche en la Bahía de Maiquillahue 1997-2007, 
Héctor Nahuelpan, Micropolíticas mapuche contra el despojo en el Chile neoliberal. La disputa por el lafkenmapu (territorio costero) en Mehuín, Izquierdas, 30, Octubre 2016: 89-123

Tesis para optar al título de Profesora de Historia y Ciencias Sociales, Universidad Austral de Chile, 2013.

Pino, Daniela, Aprendizajes y olvidos de una construcción política y patrimonial de la naturaleza: memoria colectiva del conflicto por la bahía de Maiquillahue en las nuevas generaciones de la comunidad de Mehuín, Tesis para optar al Título de Antropóloga, Universidad Austral de Chile, 2005.

Quidel, José, La idea de "Dios" y "Diablo" en el discurso ritual mapuche. Tesis de Magister en Antropología Social, Brasil, Universidade Estadual de Campinas, 2012.

Richards, Patricia, Race and the chilean miracle: neoliberalism, democracy, and indigenous rights, Pittsburgh, University of Pittsburgh Press, 2013.

Roberts, Adrienne "Privatizing social reproduction: The primitive accumulation of water in an era of neoliberalism", Antipode. A Radical Journal of Geography 40: 4, 2008, 535-560.

Salazar, Gabriel y Julio Pinto, Historia contemporánea de Chile III. La economía: mercados, empresarios y trabajadores, Santiago de Chile, LOM Ediciones, 2002.

Scott, James, Los dominados y el arte de la resistencia, México, Ediciones Era, 2000.

Seguel, Alfredo, "Crónicas de desencuentros: el gobierno de Ricardo Lagos versus el movimiento social mapuche", Nancy Yañez y José Aylwin (eds.), El gobierno de Lagos, los pueblos indígenas y el "nuevo trato", Santiago de Chile, LOM Ediciones, 2007, 101-136.

Sepúlveda, Claudia y Pablo Villarroel, "Desastre ecológico de CELCO en el Santuario Río Cruces: trizadura institucional y retroceso democrático", Sara Larraín y Pamela Poo (eds.), Conflictos por el agua en Chile: entre los derechos humanos y las reglas del mercado, Santiago de Chile, Programa Chile Sustentable, 2010, 318-338.

Skewes, Juan, “Conocimiento científico y conocimiento local. Lo que las universidades no saben acerca de lo que actores locales saben", Cinta de Moebio 19, 2004, 22-37.

Toledo, Victor, "Prima ratio. Movilización mapuche y política penal: los marcos de la política indígena en Chile, 2000-2007", OSAL 22, 2007, 253-275.

Tricot, Tito, “Lumako: punto de inflexión en el desarrollo del nuevo movimiento mapuche", Revista de Historia Actual 19, 2009, 77-96.

Zibechi, Raúl, "El estado de excepción como paradigma político del extractivismo", Claudia Composto y Mina Lorena Navarro (eds.), Territorios en disputa. Despojo capitalista, luchas en defensa de los bienes comunes naturales y alternativas emancipatorias para América Latina, México, Bajo Tierra Ediciones, 2014, 76-88. 